\title{
Chronic Idiopathic Penile Edema: Three Cases and a Review of the Literature
}

\author{
L. Raty ${ }^{1}$, V. Failla ${ }^{1}$. R. Andrianne ${ }^{2}$, M. Fillet ${ }^{2}$, D. Waltregny ${ }^{2}$ and A.F. Nikkels ${ }^{*}, 1$ \\ Departments of ${ }^{1}$ Dermatology and ${ }^{2}$ Urology, CHU du Sart Tilman, University of Liège, Belgium
}

\begin{abstract}
Chronic idiopathic penile edema (CIPE) is an exceptional entity with disabling persistent lymphedema of the penis, affecting accessorily the scrotum and the pubis. The onset presents with recurrent swelling of the external genitalia, regressing spontaneously. After 2-3 years the swelling becomes progressively persistent. Mictional and erectile dysfunctions are not uncommon. A thorough work-up including RX, ultrasound examination, CT scanning, MRI imaging, serology and extensive blood testing should be performed to exclude underlying causes, including neoplastic, infectious, vascular and inflammatory diseases. CIPE is associated with significant psychological and functional impact. Surgical correction is the sole therapeutic option. Three patients with CIPE and a review of the literature are presented in order to increase awareness of this rare condition.
\end{abstract}

Keywords: Lymphedema, male external genitalia.

\section{INTRODUCTION}

Lymphedema of the external male genitalia may be congenital or acquired [1]. Furthermore, acute episodes should be distinguished from chronic disease [2,3]. The onset may occur at any age. Acquired lymphedema may be due to fluid balance disorders, or vascular, neoplastic, infectious granulomatous and inflammatory diseases [4,5]. Only after a clueless extensive work-up, the longstanding acquired lymphedema is classified as chronic idiopathic penile edema (CIPE) [6,7]. CIPE is an exceptional entity with significant functional impotency and an important psychological impact. Three patients are presented as well as a comprehensive review of the literature.

\section{CASE REPORTS}

\section{Case 1}

A 59-year-old man without significant medical, urological or surgical history presented a sudden, nonpainful, swelling of the external genitalia. There was no prior drug intake, nor traumatism. The patient did not complain of mictional or other functional disorders. There were no systemic signs. The swelling resolved spontaneously after 2 weeks. The second episode revealed an erythematous aspect of the skin and a pitting lymphatic infiltration (Fig. 1). Palpation evidenced ill-defined subcutaneous, non-painful masses of the penis, extending towards the scrotum and the pubis. Two skin biopsies were performed under local anesthesia revealing a mixed type vasculitis and a spongiotic dermatitis. Rx work-up was not remarkable. Urologic examination showed no prostatism. The testes were normal and non-tender. Ultrasonography showed a marked echogenic thickening of the scrotal and penile subcutaneous

*Address correspondence to this author at the Department of Dermatology, University Hospital Center, University of Liège, B-4000 Liège, Belgium; Tel: +32 4366 7232; Fax: +324366 7234;

E-mail: af.nikkels@chu.ulg.ac.be tissue. A CT Scan did not reveal the presence of an inflammatory or neoplastic process, hence excluding a secondary lymphovascular swelling (Fig. 2). No lymphadenopathy was palpated. MRI imaging also showed a thickening of the subcutaneous layer of the penis. Hepatic, renal, thyroid and pancreatic functions were normal. Sedimentation rate, CEA, IgG, IgA, IgM, C3, C4, rheumatoid factor, antinuclear antibodies, ANCA, PSA and beta HCG were in normal range. CIPE was retained as final diagnosis. Currently, the swelling is stable since 2 years. There are no mictional problems but the patient suffers from erectile dysfunction and is severely bothered by his condition. Despite, the patient refused surgical intervention.

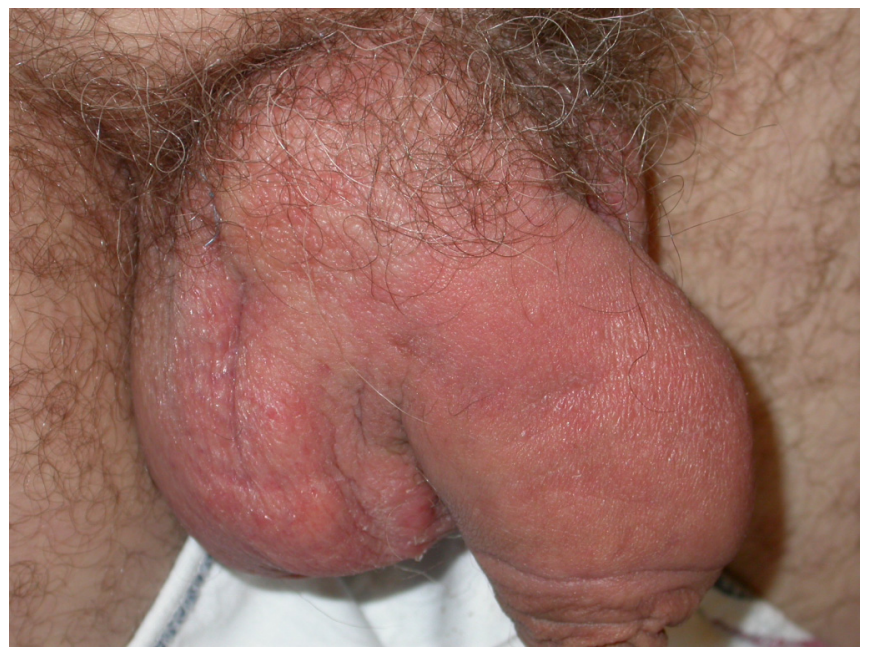

Fig. (1). Erythematous penile swelling.

\section{Case 2}

Since 3 years, a 49-year-old patient complained of recurrent episodes of painful diffuse swelling of the external genitalia. Progressively the swelling had become permanent, affecting the penis with an extension to the pubis and the 
scrotum (Fig. 3). No lymphadenopathy was observed. The skin was erythematous and itchy. There were no mictional problems. He presented erectile dysfunction with a significant impact on his quality of life. Urologic examination showed no prostatism. The testes were normal and non-tender. Furthermore, he presented a lupus-like syndrome with anti-cardiolipine antibodies and cutaneous IgG vasculitis. Previously, he had experienced 2 pulmonary embolisms and a deep venous thrombosis of the right leg. His medication consisted of salicylic acid $80 \mathrm{mg}$ /day and chloroquine $200 \mathrm{mg} /$ day. The patient could not identify any triggering factor. Later, azathioprin $2 \times 50 \mathrm{mg} / \mathrm{d}$ and methylprednisolone $4 \mathrm{mg} / \mathrm{d}$ were required to treat the cutaneous vasculitis, as topical corticosteroids were noneffective. There was however no effect on the swelling. An extensive medical work-up, including CT scanner, MRI, ultrasonography and RX were unremarkable besides the subcutaneous swelling consistent with lymphedema. Extensive blood testing remained in the normal range. The CEA, CA 19.9 and CA 125 tumor markers were negative. As final conclusion, the diagnosis of CIPE was retained. Surgical correction was proposed but denied by the patient.

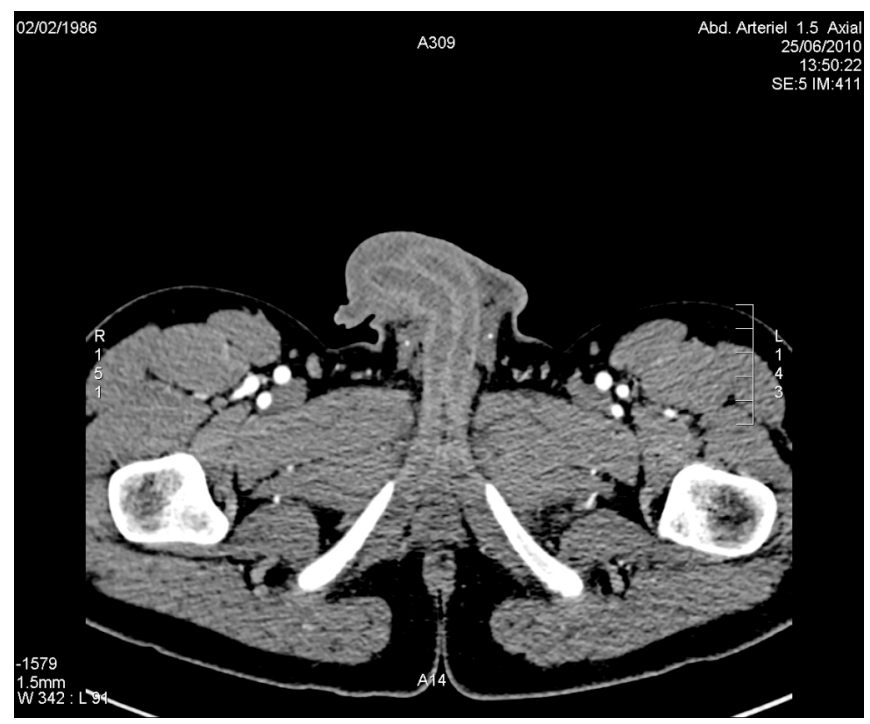

Fig. (2). CT scanning illustrating the penile lymphedematous swelling.

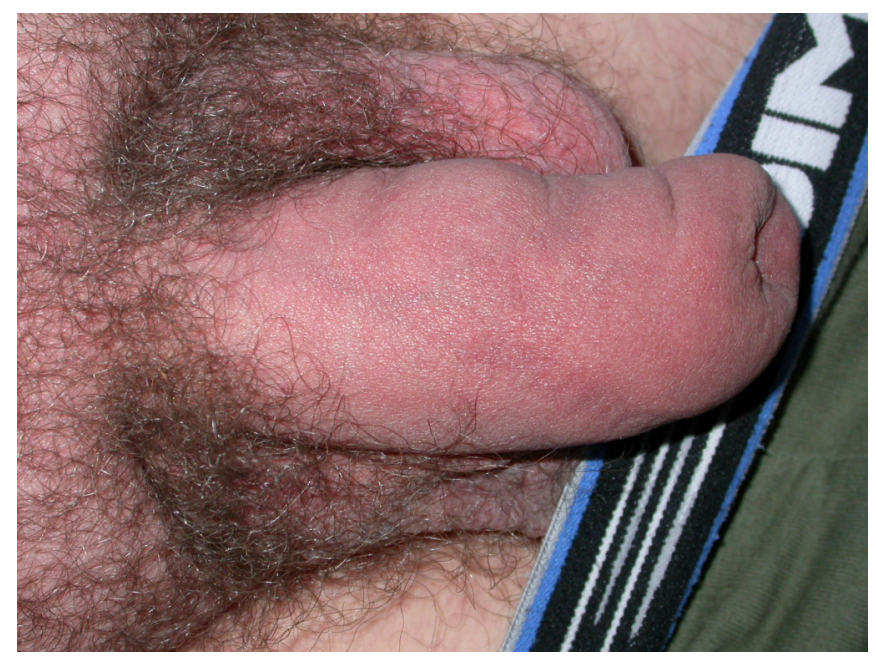

Fig. (3). Penile swelling.

\section{Case 3}

Since a year, a 54-year-old patient presented recurring, painless, swellings of the pubis, scrotum and penis, progressively becoming permanent (Fig. 4). He presented mictional problems as well as erectile dysfunction. He also presented a deformation of the penile shaft. No adenopathy was present. The penile skin was itchy and erythematous. He had no remarkable medical or surgical history. The patient did not take any medication. An internal work-up including CT scanning and ultrasonography ruled out any obstruction. MRI revealed an irregular subcutaneous thickening of the pubis, scrotum and penis. The tumor markers PSA, CEA, CA 19.9 and CA 125 were in normal range. The B cell, CD4- and CD8-T lymphocytes, monocytes and myelocyte cell counts were unremarkable. Topical potent steroids reduced the erythematous aspect of the penis and partially improved the mictional problems, without however decreasing the swelling. CIPE was retained as working diagnosis.

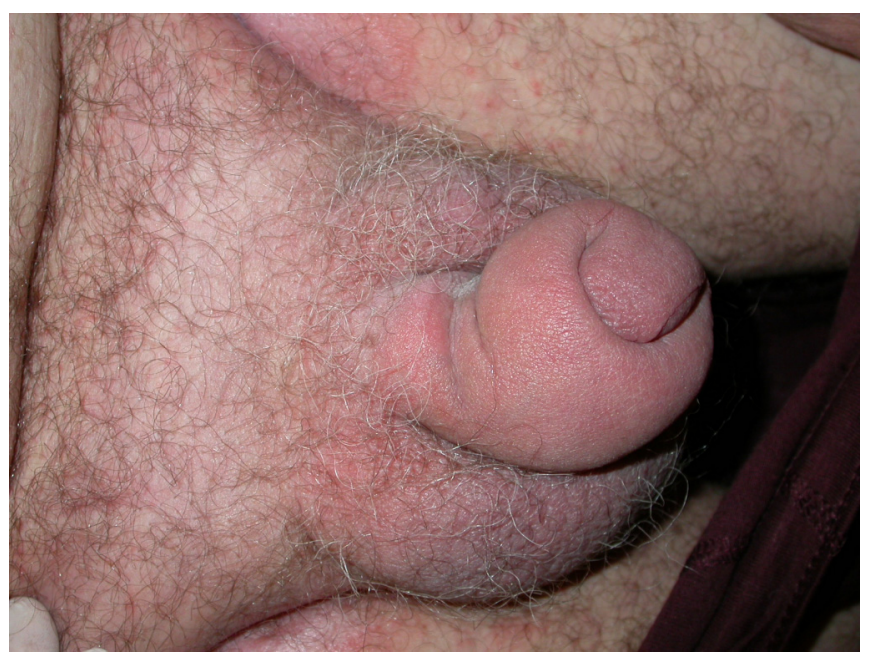

Fig. (4). Penile swelling with penile shaft deformation.

\section{DISCUSSION}

These cases illustrate typical examples of CIPE. CIPE is an exceptional disorder and epidemiological data are not available. CIPE affects preferentially the adult patient $[8,9]$, but childhood cases have been reported [10].

The clinical course is stereotypic. The initial episodes are spontaneously resolving in 1-2 weeks. In children, the swelling usually disappears more rapidly. The swelling may be more or less diffuse and does not always recur at the same anatomical site. This initial phase can last for 1-4 years. Subsequently, there is a progressive organization of the lymphedema, similar to lymphedema of the lower extremities. At this stage, CIPE becomes extremely discomforting. All the three patients presented the particular disease progression. Clinical aspects vary from slightly indurate and moderate swelling to voluminous verrucous elephantiasis of the penis and scrotum [11]. Patients may suffer from recurrent pain, pruritus [12], chronic irritation, repeated infections, drainage, and sexual dysfunction, with limitation of local hygiene, ambulation and voiding in the standing position. CIPE represents an important functional, cosmetic, psychological and emotional problem [9], as illustrated by the presented cases. 
Currently, CIPE is understood as a reduced lymphatic flow with subsequent enlargement of the penis, sometimes extending to the pubis and scrotum [8].

The diagnosis of CIPE can only be used after excluding all the potential causes of acquired chronic penile edema. In children, recurrent acquired swelling of the external genitals should exclude Crohn's disease [5]. In the adult patient, filariosis should be out ruled in endemic areas [8]. Prior surgery or radiotherapy-associated sequelae can also lead to lymphatic obstruction [13]. Congenital sequelae, neoplastic infiltration or inflammatory diseases should also be out ruled. Secondary peno-scrotal edema has also been described after amputation for septic diabetic foot [14]. Dengue hemorrhagic fever [15], acute necrotizing pancreatitis [16], hidradenitis suppurativa [13], foreign body injections or trauma with subsequent chronic infection [17] and continuous ambulatory peritoneal dialysis [18] are other rare causes. CIPE should also be distinguished from penile venereal edema [19]. Complications such as delayed healing after circumcision or other local surgical procedures are encountered. Long-term complications of CIPE include squamous cell carcinoma $[9,20]$.

The diagnostic tools exploring acquired male genital swelling include color flow Doppler [10], lymphangiography [21], CT Scanner, or MRI. Histology is non-contributive as observed in patient 1 and 2. MRI is the preferential diagnostic method, accurately evidencing the subcutaneous lymphatic edema and ruling out other causes of eventual lymphatic obstruction [22].

No medical therapy exists for CIPE. Drainage has been proposed but is not feasible in real life. The sole definitive treatment is the surgical excision of the edematous and/or fibrotic tissues, together with reconstructive methods using local flaps and skin grafts $[8,9,13,17,23,24]$. Fasciocutaneous thigh flaps have been used for coverage of the scrotum, but these flaps can alter testicular thermoregulation, sometimes causing infertility. Full thickness skin grafts have also been used for coverage. The posterior based perineal flaps preserve perirectal lymphatics, a source of collateral lymphatic drainage. Another option is the modified Charles procedure, excising the involved skin followed by scrotoplasty and midline suture simulating the scrotal raphe. Afterwards, the penis is covered with a split-thickness skin graft with a zigzag suture on its ventral surface. This treatment option of CIPE is easily reproducible and allows better local hygiene, easier ambulation, voiding in the standing position, resuming sexual intercourse and better cosmetic results [25]. Other authors also related excellent cosmetic and functional results using this technique $[22,24]$. Wide excision of the involved area with subsequent coverage of exposed areas with split-thickness skin grafts in a singlestage procedure is another surgical technique. All the patients had excellent cosmetic results without recurrence of CIPE or compromise of sexual function postoperatively [23]. In short, once CIPE is a stable disease, surgical treatment is recommended and the functional and cosmetic results are excellent and patient rehabilitation is likely. It is however noteworthy that many patients refrain from surgical treatment, as in our cases.

In conclusion, CIPE is an exceptional and probably underrecognized entity, with disabling lymphedema affecting the penis, the scrotum and the pubis. The resolving episodes become progressively permanent. Mictional problems are rare but erectile dysfunction is usual. MRI is the preferential diagnostic method. Surgical correction is the only curative option.

\section{REFERENCES}

[1] Smeltzer DM, Stickler GB, Schirger A. Primary lymphedema in children and adolescents : a follow-up study and review. Pediatrics 1985; 76: 206-18.

[2] McDougal WS. Lymphedema of the external genitalia. J Urol 2003; 170: 711-6.

[3] van Langen AM, Gal S, Hulsmann AR, De Nef JJ. Acute idiopathic scrotal oedema: four cases and a short review. Eur J Pediatr 2001; 160: 455-6.

[4] Geyer H, Geyer A, Schubert J. Erysipelas and elephantiasis of the scrotum. Surgical and drug therapy. Urologe-Ausgabe A 1995; 34: 59-61.

[5] Murphy MJ, Kogan B, Carlson JA. Granulomatous lymphangitis of the scrotum and penis. Report of a case and review of the literature of genital swelling with sarcoidal granulomatous inflammation. J Cutan Pathol 2001; 28: 419-24.

[6] Thomas JA, Matanhelia SS, Rees RWM. Recurrent adult idiopathic penile oedema : a new clinical entity ? Hosp Update 1993; 667-8.

[7] Porter W, Dinneen M, Bunker C. Chronic penile lymphedema: a report of 6 cases. Arch Dermatol 2001; 137: 1108-10.

[8] Muehlberger T, Homann HH, Kuhnen C, Vogt PM, Steinau HU. Etiology, clinical aspects and therapy of penoscrotal lymphedema. Chirurg 2001; 72: 414-8.

[9] Halperin TJ, Slavin SA, Olumi AF, Borud LJ. Surgical management of scrotal lymphedema using local flaps. Ann Plast Surg 2007; 59: 67-72.

[10] Brandes SB, Chelsky MJ, Hanno PM. Adult acute idiopathic scrotal edema. Urology 1994; 44: 602-5.

[11] Luelmo J, Tolosa C, Prats J, Bella MR, Saez A, Pellicé C Jr. Tumorous lymphedema of the penis. Report of verrucous elephantiasis. A brief case. Preliminary note. Actas Urol Esp 1995; 19: $585-7$.

[12] Tebbe-Gholami M, Roest W. A man with acute scrotal swelling. Ned Tijdschr Geneeskd 2010; 154: A16.

[13] García-Tutor E, Botellé del Hierro J, San Martín Maya A, et al. Surgical treatment of penile lymphedema associated with hidradenitis suppurativa. Acta Urol Esp 2005; 29: 519-22.

[14] Fahal AH, Suliman SH, Sharfi AR, el Mahadi EM. Acute idiopathic scrotal oedema in association with diabetic septic foot Diabetes Res Clin Pract 1993; 21: 197-200.

[15] Chen TC, Lu PL, Chen YH, Tsai JJ, Chen TP. Dengue hemorrhagic fever complicated with acute idiopathic scrotal edema and polyneuropathy. Am J Trop Med Hyg 2008; 78: 8-10.

[16] Choong KK. Acute penoscrotal edema due to acute necrotizing pancreatitis. J Ultrasound Med 1996; 15: 247-8.

[17] Malloy TR, Wein AJ, Gross P. Scrotal and penile lymphedema: surgical considerations and management. J Urol 1983; 130: 263-5.

[18] Abraham G, Blake PG, Mathews RE, Bargman JM, Izatt S, Oreopoulos DG. Genital swelling as a surgical complication of continuous ambulatory peritoneal dialysis. Surg Gynecol Obstet 1990; 170: 306-8.

[19] Wright RA, Judson FN. Penile veneral edema. JAMA 1979; 241: 157-8.

[20] Hadway P, Lynch M, Corbishley CM, Mortimer PS, Watkin NA. Squamous cell carcinoma of the penis in a patient with chronic isolated penile lymphedema. Urol Int 2006; 76: 87-8. 
[21] Samsoen M, Deschler JM, Servelle M, Raiga JC, Lelièvre G, Tardieu JC. Lymphoedema of penis and scrotum: two observations. Ann Dermatol Venereol 1981; 108: 541-6.

[22] Garaffa G, Christopher N, Ralph DJ. The management of genital lymphoedema. BJU Int 2008; 102: 480-4.

[23] Morey AF, Meng MV, McAninch JW. Skin graft reconstruction of chronic genital lymphedema. Urology 1997; 50: 423-6.
[24] Zacharakis E, Dudderidge T, Zacharakis E, Ioannidis E. Surgical repair of idiopathic scrotal elephantiasis. South Med J 2008; 101: 208-10.

[25] Modolin M, Mitre AI, da Silva JC, et al. Surgical treatment of lymphedema of the penis and scrotum. Clinics 2006; 61: 289-94.

Received: November 3, 2010

Revised: November 13, 2010

Accepted: November 16, 2010

(C) Raty et al.; Licensee Bentham Open.

This is an open access article licensed under the terms of the Creative Commons Attribution Non-Commercial License (http://creativecommons.org/licenses/by-nc/ $3.0 /$ ) which permits unrestricted, non-commercial use, distribution and reproduction in any medium, provided the work is properly cited. 